\title{
Universidades, ditadura e cultura política
}

Rodrigo Patto Sá Motta*

\section{Resumo}

0 texto empreende um esforço analítico visando compreender a essência da política universitária da ditadura, que foi eivada de paradoxos e ambiguidades. Lançando mão da categoria cultura política, a proposta é mostrar que as relações do Estado com a comunidade acadêmica foram marcadas por negociações e acomodações - paralelamente às ações repressivas - e que tais estratégias estão inscritas nas tradições políticas do país, sobretudo quando estão em cena as elites sociais.

\section{Palavras-chave}

Ditadura. Universidade. Cultura política.

\begin{abstract}
This is an analytical effort to understand the essence of the policy for universities during the military dictatorship in Brazil, which was stained with paradoxes and ambiguities. Launching hand of the category political culture, the proposal is to show that the relations between State and academic community were marked by negotiations and accommodations - in parallel to the repressive actions - and that such strategies are entered in political traditions of the country, especially when the social elites are on the scene.
\end{abstract}

\section{Keywords}

Dictatorship. University. Political culture.

\footnotetext{
* Doutor em História pela Universidade de São Paulo (USP), pesquisador bolsista do Conselho Nacional de Desenvolvimento Científico e Tecnológico (CNPq) e professor do Departamento de História da Universidade Federal de Minas Gerais (UFMG). E-mail: rodrigosamotta@yahoo. com.br .
} 


\section{Introdução}

Este artigo foi redigido com base em publicação recente, o livro As universidades e o regime militar. ${ }^{1}$ A pesquisa para este trabalho foi desenvolvida ao longo de seis anos e mobilizou diferentes e volumosos acervos documentais, começando pelos arquivos que foi possível localizar das extintas ASI (Assessorias de Segurança e Informações) universitárias. No campo das agências de vigilância política, também foram pesquisados arquivos de alguns Departamentos de Ordem Política e Social (Dops) estaduais, assim como os acervos do Serviço Nacional de Informações (SNI) e do Conselho de Segurança Nacional (CSN). Foram pesquisados ainda alguns arquivos norte-americanos, principalmente os National Archives and Records Administration e os registros da United States Agency for International Development (Usaid). Finalmente, foram realizadas cerca de 50 entrevistas com pessoas que eram estudantes e/ou professores nos anos 1960 e 1970.

O objetivo central da pesquisa era compreender e explicar o impacto da ditadura sobre as universidades, sobretudo as políticas adotadas pelo regime autoritário para o ensino superior e o modo como a comunidade acadêmica vivenciou esse processo. Além disso, a intenção era construir um modelo analítico capaz de dar conta das complexidades do experimento autoritário brasileiro, que não se enquadra bem em modelos simplistas e binários. A pesquisa revelou a existência de muitos paradoxos nas relações da ditadura com a comunidade acadêmica, que o autor procurou explicar lançando mão do conceito cultura política. A hipótese, que será alinhavada nas páginas seguintes, é que as ambiguidades e os paradoxos da ditadura podem ser melhor compreendidos se os inscrevemos na tradição política brasileira, de que são tributários. Nessa linha, as palavras-chave são conciliação e acomodação. Levar em conta esses aspectos é importante não apenas para entender o funcionamento da ditadura, mas também sua peculiar transição à democracia. Vejamos.

${ }^{1}$ MOTTA, Rodrigo Patto Sá. As universidades e o regime militar. Cultura política brasileira e modernização autoritária. Rio de Janeiro: Jorge Zahar, 2014. 
Muito ainda há a analisar e explicar sobre o regime militar brasileiro, cuja história é eivada de ambiguidades e paradoxos, algumas vezes raiando à contradição. O Estado autoritário foi marcado por indefinições ideológicas, dividido entre assumir-se como ditadura ou conciliar com os princípios liberais, ao passo que oscilava entre o nacionalismo desenvolvimentista e os princípios do livre mercado. Ao mesmo tempo que demonizou o "populismo" de seus antecessores, a ditadura não só manteve intactas como ampliou as estruturas corporativas herdadas, além de ter criado um sistema previdenciário universal, sob controle do Estado.

Considerando as ações repressivas, que produziram centenas de mortos e um número ainda maior de torturados, em certas ocasiões as perseguições aos esquerdistas foram contornadas com base em interesses pragmáticos ou em arranjos pessoais. O regime era convictamente anticomunista, porém manteve relações corretas com Moscou e o bloco socialista (exceto Cuba), e, enquanto a leitura de Mao e Guevara era proibida, Marx podia circular nos bancos universitários e mesmo nas bancas de revistas. Além disso, os vitoriosos de 1964 atacaram as promessas do governo deposto, mas se apropriaram de alguns de seus projetos e ideias, como a reforma universitária, que implantaram de modo autoritário e elitista.

Nessa direção, o conceito de modernização conservadora pode servir como síntese dos paradoxos e contradições do regime militar. O grande paradoxo da ditadura era expressar, simultaneamente, impulsos conservadores e modernizadores que, por vezes, geraram ações contraditórias. O desejo modernizador implicava desenvolvimento econômico e tecnológico, e, portanto, aumento dos contatos com o exterior e mobilidade das pessoas, além de expansão industrial e mecanização agrícola. Com isso, levavase ao aumento da urbanização e do operariado fabril, gerando potenciais tensões e instabilidade nas relações sociais e de trabalho. Já o impulso conservador estava ligado à vontade de preservar a ordem social e os valores tradicionais, o que insuflava o combate às utopias revolucionárias e outras formas de subversão e "desvio", aí incluídos questionamentos à moral e aos comportamentos convencionais.

Paradoxalmente, o poder autoritário construído para expurgar as esquerdas e manter a ordem social foi usado também para alavancar os projetos modernizadores, removendo obstáculos e impondo os caminhos escolhidos pelos tecnocratas. Daí haver motivos para oscilar na escolha da melhor adjetivação para o regime militar brasileiro: modernização conservadora ou autoritária? A resposta é que ele foi simultaneamente 
autoritário e conservador.

Importa perceber que esses paradoxos e contradições derivavam da própria ossatura política do regime, resultado da aproximação de grupos ideologicamente distintos, unidos apenas por pauta negativa comum. $\mathrm{O}$ regime militar tinha três fontes ideológicas principais: nacionalismo autoritário, liberalismo e conservadorismo (e mais a tradição anticomunista, servindo como elo entre elas), cada uma com nuanças e peculiaridades que apontavam para políticas diferentes. O caráter paradoxal do regime militar, em grande medida, devia-se às pressões diferentes exercidas por tais grupos, que por vezes eram conciliadas, enquanto, por outras, eram atendidas umas em detrimento das outras. Em certas circunstâncias, já que diferentes grupos ocupavam lugares distintos no aparelho do Estado, políticas contraditórias foram adotadas ao mesmo tempo.

Tratava-se de regime político em cujos discursos se afirmavam, ao mesmo tempo, os valores democráticos e liberais, a defesa da autoridade e da pátria "una e indivisa", e a exaltação da família e da ordem social tradicional. Para explicar a indecisão do regime militar entre ditadura e respeito a certas instituições liberais, há que levar em conta, também, o fato do seu evento originário (o "31 de março") ser considerado um movimento em defesa das instituições democráticas, supostamente ameaçadas pela esquerda e por Goulart. Assim, no imaginário da "Revolução de 1964", os temas da liberdade e da democracia ocupavam lugar importante, opondo obstáculos aos que desejavam estabelecer regime ditatorial puro.

Evidentemente, isso não impediu a violência repressiva, tampouco que o conceito de democracia se prestasse às mais diversas apropriações. Ainda assim, as representações associando "1964" a significados liberais não se restringiram a efeitos retóricos, pois serviram de arma aos setores moderados do regime para conter sua ala radical. Não que houvesse entre eles, efetivamente, democratas. Tais setores preferiam um tipo de autoritarismo liberal capaz de garantir estabilidade, afastar os riscos de mudança social, e, ao mesmo tempo, evitar que a repressão muito intensa tornasse a luta armada a única opção dos oposicionistas.

\section{Cultura política}

$\mathrm{O}$ argumento principal a ser desenvolvido neste texto é que o influxo da cultura política pode explicar as peculiaridades do autoritarismo brasileiro, 
que se destacam mais quando fazemos comparações com as experiências dos países vizinhos. Aliás, os estudos sobre cultura política ganham maior densidade quando é possível estabelecer padrões comparativos. Com base no conhecimento disponível sobre as ditaduras do Cone Sul, pode-se perceber tanto similaridades quanto singularidades na comparação com o caso brasileiro. A ideia é que as diferenças guardam relação com as respectivas culturas políticas, muito embora não se adote uma compreensão essencialista desse conceito. A proposta analítica é que os paradoxos, as ambiguidades e as estratégias de acomodação presentes no caso brasileiro têm origem, ao menos em parte, no repertório que integra as tradições políticas do país.

Entre os pontos que distinguem o regime militar brasileiro, podem ser destacados: o projeto econômico nacional-desenvolvimentista, a manutenção em vigor (embora de modo precário) de instituições liberais, o menor número de mortes e desaparecimentos provocados pela repressão política, uma taxa mais elevada de absolvições nos julgamentos de crimes políticos ${ }^{2}$, e uma maior tolerância com intelectuais e valores culturais de esquerda ${ }^{3}$, que continuaram a circular durante a Ditadura.

Antes de prosseguir, é indispensável conceituar cultura política, categoria de análise desenvolvida por cientistas sociais norte-americanos nos anos 1950 e 1960 (sobretudo Gabriel ALMOND e Sidney VERBA), que tem sido apropriada seletivamente pela historiografia. O quadro teórico originalmente desenvolvido foi submetido a severas críticas por sua proximidade ideológica com os preceitos da Guerra Fria e por hierarquizar, embora sutilmente, as diferentes culturas políticas. Em anos recentes, o conceito tem sido apropriado pela historiografia, sob o impacto da "virada culturalista". Influenciados pela força ascendente do paradigma culturalista e

\footnotetext{
${ }^{2}$ Cf. PEREIRA, Anthony, que comparou o funcionamento da justiça política das ditaduras do Brasil, Argentina e Chile. No entanto, Pereira não considera a cultura política fator relevante para explicar por que no Brasil os réus políticos foram absolvidos em maior proporção. Political (in) justice. Authoritarianism and the rule of law in Brazil, Chile and Argentina. Pittsburgh: University of Pittsburgh Press, 2005.

${ }^{3}$ Sobre as relações paradoxais entre o Estado autoritário e produtores culturais e artistas de esquerda, ver RIDENTI, Marcelo. Brasilidade revolucionária: um século de cultura e política. São Paulo: UNESP, 2010, pp.103-106 e também NAPOLITANO, Marcos. "Vencer Satã só com orações": políticas culturais e cultura de oposição no Brasil dos anos 1970. In: OLLEMBERG, Denise Rollemberg; Samantha Quadrat (Org.); A construção social dos regimes autoritários Legitimidade, consenso e consentimento no século XX. Brasil e América Latina. Rio de Janeiro: Civilização Brasileira, 2010. p.145-174
} 
interessados em renovar o enfoque da História Política, alguns historiadores redescobriram a categoria cultura política, entre eles os franceses JeanFrançois Sirinelli e Serge Berstein ${ }^{4}$, que propuseram apropriação, que exclui os elementos funcionalistas e eventualmente etnocêntricos presentes na formulação original.

Embora a categoria seja utilizada em acepção diferente da versão dos cientistas sociais norte-americanos, em um ponto central a inspiração teórica é a mesma: o entendimento de que a cultura - em sentido antropológico influencia as decisões e ações políticas. Tal compreensão implica certa crítica ao paradigma liberal-racionalista, que vê os agentes políticos como seres movidos essencialmente por ideias e interesses. A perspectiva culturalista, portanto a aplicação do conceito cultura política, supõe a convicção de que os homens agem também movidos por paixões e sentimentos, como medo, ódio e esperança; são mobilizados por meio de representações e imaginários que constroem mitos e heróis exemplares, bem como inimigos odientos; e tomam decisões por influência de valores construídos em torno da família, nação ou religião. No entanto, isso não implica estabelecer uma espécie de determinismo culturalista, desprezando a importância do interesse e da escolha individual. A abordagem cultural é valiosa e inspiradora, mas, se for encarada de maneira absoluta, pode empobrecer, em lugar de enriquecer o conhecimento. No momento da decisão, os agentes têm à disposição um leque de opções, e os fatores culturais (sentimentos, identidades, valores) podem exercer maior ou menor influência, a depender do contexto e dos atores em cena.

Nessa perspectiva, pode ser adotada a seguinte definição para cultura política, sem a pretensão de excluir outras acepções possíveis para um conceito, que é, evidentemente, polissêmico: conjunto de valores, tradições, práticas e representações políticas partilhado por determinado grupo humano, expressando identidade coletiva e fornecendo leituras comuns do passado, assim como inspiração para projetos políticos direcionados ao futuro.

\footnotetext{
${ }^{4}$ Suas obras principais são: BERSTEIN, Serge. "A cultura política”. In: Jean-Pierre Rioux; JeanFrançois Sirinelli (Org.); Para uma história cultural. Lisboa: Estampa, 1988; BERSTEIN, Serge (org.). Les cultures politiques en France. Paris: Éditions du Seuil, 1999; BERSTEIN, Serge. "Culturas políticas e historiografia”. In: Cecília Azevedo; Denise Rollemberg; Maria Fernanda Bicalho; Paulo Knauss; Samantha Viz Quadrat (Orgs.); Cultura Política, Memória e Historiografia. Rio de Janeiro: FGV, 2009.
} 
Tal conceituação de cultura política pode ser utilizada tanto no plural quanto no singular, ou seja, pode ser aplicada tanto a conjuntos nacionais (cultura política brasileira, por exemplo), quanto a projetos políticos específicos, em matriz pluralista: comunismo, liberalismo, conservadorismo, fascismo etc. ${ }^{5}$ A proposta aqui, portanto, é considerar a existência de uma cultura política brasileira que convive e interage com culturas políticas específicas, como o liberalismo ou o socialismo que, por sua vez, são influenciados por traços da cultura nacional.

No entanto, a existência de padrões e valores gerais não significa que todas as pessoas aderem e se comportam de modo uniforme; trata-se apenas de uma orientação geral que, não obstante, é suficientemente influente ao ponto de configurar traço cultural marcante. Por outro lado, não se trata de comportamentos inexoravelmente determinados por estruturas culturais preexistentes. O campo da política supõe o protagonismo de agentes que fazem escolhas: há sempre margem para a opção entre diferentes caminhos de ação. $\mathrm{O}$ argumento é que as escolhas podem sofrer a influência da cultura política, que oferece aos agentes alguns padrões de ação já inscritos nas tradições, mais atraentes e viáveis por terem gerado sucesso em ocasiões anteriores. Assim, não há por que supor oposição entre a influência de padrões culturais e o arbítrio dos agentes políticos. A cultura política exerce influência efetiva, porém não por implicar algum tipo de atavismo, mas por indicar aos atores caminhos e estratégias com maiores chances de sucesso, tornando-se escolhas interessantes para os agentes envolvidos.

Uma última observação para esclarecer o sentido atribuído à cultura política, enfatizando o cuidado para evitar generalizações excessivas. Propor a existência de traços culturais específicos no campo político não implica a postulação de uma excepcionalidade brasileira. Alguns dos elementos característicos de tal cultura política podem ser encontrados em outros espaços nacionais. Nessa direção, há que considerar os debates já clássicos em torno do "iberismo", que teria marcado a formação nacional brasileira, apontando para laços de afinidade cultural em relação a algumas nações

\footnotetext{
${ }^{5}$ SCf. MOTTA, Rodrigo Patto Sá. "Desafios e possibilidades na apropriação de cultura política pela historiografia”. In Culturas Políticas na História: Novos Estudos. Belo Horizonte: Argvmentvm, 2009. p. 13-37.
} 
europeias e latino-americanas. ${ }^{6}$ No entanto, defende-se que o legado de outros povos combinou-se no desenrolar da experiência histórica nacional e gerou resultado original, melhor percebido quando se compara a história política brasileira com a de países em situação semelhante.

Discussões sobre o tema são tão antigas quanto a formação nacional brasileira, já que a identificação de características distintivas entre os povos é parte do processo de imaginação nacional. Tais debates mobilizaram tanto motivação acadêmica quanto impulsos folclorizantes, que, particularmente no último caso, se prestaram a manipulações políticas. Desde o século XIX, vários traços foram apontados como singularidades brasileiras, tanto por viajantes quanto por pensadores sociais destacados, a exemplo de Gilberto Freire, Sérgio Buarque de Hollanda, Oliveria Vianna, Raymundo Faoro e Roberto DaMatta. ${ }^{7}$ Esses autores, entre outros, apontaram características ou comportamentos políticos típicos dos brasileiros, embora sem mobilizar cultura política, até porque, na maioria dos casos, suas reflexões antecederam o debate acadêmico sobre o conceito. Não obstante, é interessante destacar a situação excepcional de Oliveira Vianna, que fez uso pioneiro de cultura política em obra publicada em 1949. No livro Instituições políticas brasileiras, Oliveira Vianna usou cultura política para denominar o conjunto de costumes e tradições políticas brasileiras e, embora não tenha apresentado definição precisa, o sentido é próximo do que foi desenvolvido posteriormente pelas ciências sociais. ${ }^{8}$

\footnotetext{
${ }^{6}$ Cf FAORO, Raymundo. Os donos do poder: a formação do patronato político brasileiro. 2 ed. Porto Alegre: Globo, 1975 e BARBOZA FILHO, Rubem. Tradição e artifício. Iberismo e barroco na formação americana. Belo Horizonte: UFMG, 2000.

${ }^{7}$ Vale mencionar que alguns brazilianistas argutos também se interessaram pelo tema, como Philippe Schmitter, que mencionou o pioneirismo de Oliveira Vianna no uso do conceito cultura política. Cf. SCHMITTER, Philippe. Interest conflict and political change in Brazil. Stanford: Stanford University Press, 1971.

${ }^{8}$ VIANNA, Francisco José de Oliveira. Instituições políticas brasileiras. São Paulo: José Olympio, 1949. É importante considerar que a expressão já circulava no Brasil desde a famosa publicação do Estado Novo Cultura Política, iniciada em 1941. Os editores não definiram o sentido da expressão, mas pode-se inferir que ela expressava o desejo da elite estadonovista de oferecer cultura política a um povo considerado "inculto" e incapaz de autogoverno. A propósito, é importante destacar que não partilho o pessimismo de Vianna acerca das virtudes políticas do povo brasileiro, tampouco suas conclusões autoritárias, embora reconheça a relevância de sua contribuição para o tema da cultura política.
} 
Pois bem, a proposta é perceber nesse conjunto de características uma unidade (embora descartando quaisquer determinismos) que constitui e dá forma a uma cultura política, em outras palavras, um repertório de representações e práticas que influenciam os comportamentos políticos de muitos brasileiros. Passo a apresentar um esboço dos elementos centrais de tal cultura política para, em seguida, enfatizar alguns de seus aspectos e o modo como incidiram no período do Regime Militar, sobretudo em sua política universitária.

Primeiramente, para caracterizar uma cultura política enquanto tal, é necessária a existência de um imaginário, no caso em tela, um imaginário nacional, um conjunto de representações capaz de instituir o grupo como comunidade política. Desse conjunto fazem parte heróis, vilões, eventos marcantes, guerras etc., uma gama de representações construídas por meio de imagens mentais ou visuais que são preservadas, reproduzidas e reapropriadas ao longo do tempo, processo em que atuam tanto a memória como a historiografia, além da literatura, a cultura visual e as diferentes mídias. Existem excelentes estudos dedicados ao campo do imaginário político brasileiro, mas se trata de tema ainda não esgotado e carente de obras de síntese. ${ }^{9}$

Além do imaginário, outro ponto essencial para identificar uma cultura política é a presença de comportamentos e valores políticos típicos do grupo. Os ensaístas e pesquisadores que visitaram o tema destacaram uma série de questões, que serão elencadas a seguir sem a preocupação de se analisar (e criticar) todas de maneira aprofundada. Nas obras desses autores, um dos temas mais fortes é o patrimonialismo, ou seja, a tendência a confundir os bens públicos e os privados, supostamente uma herança ibérica, questão analisada, sobretudo, por Raimundo Faoro. Outro nome clássico do nosso pensamento político, Oliveira Vianna propôs que o personalismo (ou o privatismo) seria elemento central da cultura política, marcada, portanto,

\footnotetext{
${ }^{9}$ Um das contribuições mais relevantes é a de José Murilo de Carvalho, notadamente em $A$ Formação das Almas. O imaginário da República no Brasil. São Paulo: Companhia das Letras, 1990. Entre os textos de referência para o estudo dos imaginários políticos podem ser citados: ANSART, Pierre. Ideologias, conflitos e poder. Rio de Janeiro: Zahar 1978; BACZKO, Bronislaw. A imaginação social. In: Edmund Leach et al. (Ed.); Anthropos-Homem. Lisboa, Imprensa Nacional/Casa da Moeda, 1985; e GIRARDET, Raoul. Mitos e mitologias políticas. São Paulo: Companhia das Letras, 1987.
} 
pela primazia dos laços pessoais em detrimento das relações impessoais. Trocando em miúdos, na sua atuação política, os cidadãos privilegiariam a fidelidade a laços de parentesco, amizade, compadrio ou patronagem, à revelia de normas universais, com baixa adesão a projetos políticos impessoais. Essa descrição empreendida por Oliveira Vianna não está muito distante do homem cordial enxergado por Sérgio Buarque de Hollanda, embora esse autor não tenha ultrapassado a fase de esboço do seu insight. Em linha parecida, também, podem ser situadas as análises de Roberto DaMatta sobre a "Casa e a Rua", que apontam igualmente para a tradicional prevalência de laços sociais privados (Casa) em detrimento dos espaços e instituições públicas (Rua).

Vale a pena notar que a influência do "personalismo" analisado por Oliveira Vianna permanece presente nos dias atuais. A maioria dos cidadãos brasileiros ainda faz suas escolhas eleitorais privilegiando pessoas em detrimento de instituições, e acolhe bem líderes carismáticos, depositando neles suas esperanças e anseios. Pesquisas recentes de cientistas políticos que trabalham com a categoria cultura política, baseadas em surveys e estudos comparativos com outros países da América Latina, mostram como tais comportamentos políticos continuam arraigados entre os brasileiros. ${ }^{10}$

Além dos temas já apontados, poderíamos incluir como elementos integrantes da cultura política brasileira o clientelismo, o elitismo (e seu par inseparável, a exclusão popular dos espaços de decisão), a frágil identificação dos cidadãos com os partidos, o pouco apreço e a escassa participação nos espaços públicos. Alguns autores apontaram que a fraca participação popular na política institucional não significa ignorância e pode representar, bem ao contrário, a sagaz percepção de que o universo da "grande" política exclui os setores sociais subalternos. Seria o bilontrismo, uma disposição popular para

\footnotetext{
${ }^{10}$ José Álvaro Moisés analisou pesquisas de opinião com dados referentes a 18 países latinoamericanos. A conclusão é que a maioria dos brasileiros mantém atitudes ambivalentes diante das instituições liberal-democráticas: a desconfiança em relação às instituições se combina com a manifestação formal de apreço por valores democráticos, o que sugere a adesão de muitos a uma espécie de democracia sem partidos ou congresso. De acordo com os dados da pesquisa, o percentual de cidadãos adeptos de valores democráticos é um dos mais baixos da América Latina, enquanto o grupo dos ambivalentes (que combinam valores democráticos e autoritários) no Brasil é o mais alto da região MOISÉS, José Álvaro. Cultura política, instituições e democracia. Lições da experiência brasileira. Revista Brasileira de Ciências Sociais. São Paulo, vol.23, no66, 2008, pp.11-43.
} 
perceber o caráter elitista da política brasileira e recusar-se à participação, para evitar o logro. ${ }^{11}$ Entretanto, cabe questionar, tal forma de sagacidade não significaria, ao mesmo tempo, uma manifestação de impotência? A recusa à participação, ainda que inspirada por um olhar sagaz, não contribuiria para a manutenção das desigualdades políticas e sociais?

Tal linha interpretativa sofreu muitas críticas, acusada de pretender aplicar ao Brasil modelos de cidadania criados em outros centros, o que levaria à sobrevalorização de inevitáveis ausências. Apontar tais características implicaria análises que desvalorizam a capacidade do povo brasileiro, rebaixam-no, ao passo que a mudança de foco na direção de outras dimensões da vida social, deixando de lado a política institucional, revelaria manifestações pujantes. Não interessa agora entrar em tais polêmicas, pois não se trata de exaltar ou rebaixar a cultura política brasileira. No entanto, ainda que a cultura popular tenha diversas expressões de força e vivacidade, segue o problema da frágil participação nos temas de maior interesse coletivo, que têm relação com outros problemas estruturais, como as taxas de desigualdade social, ainda entre as maiores do mundo.

Passo a analisar com mais cuidado uma característica tradicionalmente considerada parte da cultura brasileira, enfatizando sua incidência no campo político. Refiro-me à tendência à flexibilidade, à conciliação, ou à negociação de conflitos, cuja influência no regime militar pretendo demonstrar nas páginas seguintes. Trata-se de tema clássico entre ensaístas e pensadores sociais, mobilizando tanto defensores como críticos, e que está em pauta pelo menos desde Gilberto Freire, tendo merecido um livro de José Honório Rodrigues. ${ }^{12}$ Temos larga história de grandes conciliações políticas (1822, 1853, 1889, 1961, 1979, 1985), quando arranjos foram mobilizados para evitar conflitos graves e encontrar saídas políticas aceitáveis para os grupos envolvidos. Tais estratégias tendem a encontrar maior sucesso quando o jogo político não inclui segmentos sociais subalternos, portanto, quando se trata de arranjos entre grupos pertencentes às elites sociais e políticas. Nos momentos em que ocorrem episódios de maior mobilização popular,

\footnotetext{
${ }^{11}$ Cf. CARVALHO, José Murilo de. Os bestializados. O Rio de Janeiro e a República que não foi. São Paulo: Companhia das Letras, 1987 (sobretudo o capítulo 5).

${ }^{12}$ RODRIGUES, José Honório. Conciliação e reforma no Brasil: um desafio histórico-cultural. Rio de Janeiro: Nova Fronteira, 1965.
} 
a tendência a soluções violentas é mais provável (como o caso de Canudos, por exemplo), com menores chances para a mobilização de iniciativas conciliatórias.

Especulando mais, pode-se dizer que tal fenômeno guarda relação com certos aspectos da cultura brasileira já apontados por outros autores: a tendência a negar/escamotear conflitos, diferenças e distâncias sociais, com boa disposição para a incorporação (do estrangeiro, p.e.), a tolerância/ flexibilidade (religiosa, p.e.) e a mistura racial. Evidentemente, não se trata de aceitar o velho mito da democracia racial, que esconde o racismo peculiar ao Brasil. No entanto, como todo mito poderoso, esse também se assenta em certos elementos "reais", como a alta taxa de mestiçagem e a possibilidade do "branqueamento" e ascensão social para alguns indivíduos "não brancos". A propósito, a larga aceitação do mito da democracia racial entre os brasileiros ${ }^{13}$, inclusive muitos cidadãos negros, serve de comprovação ao argumento defendido aqui: ela confirma que a disposição para aceitar fórmulas negadoras/escamoteadoras dos conflitos sociais é muito forte no Brasil, contribuindo para atenuar uma das questões com maior potencial de gerar conflitos políticos no país.

Antes de representar um caráter bondoso dos brasileiros ou qualquer adjetivo moral equivalente, a acomodação representa uma estratégia inteligente. Escamotear e conciliar conflitos têm sido meios eficientes para reduzir tensões sociais e, com isso, manter o poder político e privilégios sociais, facilitando a manutenção do status quo. Entretanto, é necessária a presença de disposição cultural favorável, pois apenas o cálculo estratégico não é suficiente para explicar a adesão a tal comportamento. Claro, na história brasileira houve violência política, tanto mais intensa quanto maior a presença de grupos populares, e o nosso quadro de violência social "comum" é muito elevado, como qualquer habitante das grandes cidades bem sabe. Não

\footnotetext{
${ }^{13}$ Uma evidência estatística da dificuldade dos brasileiros para perceberem conflitos raciais: em maio de 1963, o IBOPE realizou uma pesquisa de opinião com 1010 entrevistados na Guanabara. Vários temas foram explorados na entrevista, mas interessa aqui destacar uma pergunta: "Na sua opinião o Brasil tem algum problema racial?”. O resultado foi que $60 \%$ responderam não e apenas $34 \% \operatorname{sim}$. Curiosamente, e significativamente, a pergunta seguinte explorou a opinião dos cariocas sobre o racismo nos EUA, e a maioria opinou que as relações entre brancos e negros naquele país eram ruins. A pesquisa se encontra em National Archives and Records Administration II, RG 306, \# 1015, caixa 15, pasta 2. College Park, MD, EUA.
} 
obstante, temos uma tendência forte para a conciliação política, fenômeno difícil de negar dada sua ampla recorrência - e atualidade.

Chegando ao ponto principal deste trabalho, pretendo mostrar que tendências conciliatórias também se manifestaram no regime militar, apesar do autoritarismo intrínseco e maior disposição para a violência política. Centenas de pessoas morreram naqueles anos em luta contra a ditadura e um número maior foi torturado, removido de cargos públicos ou partiu para o exílio. Ainda assim, a influência da cultura política se fez presente, e jogos de acomodação e estratégias conciliatórias ocorreram simultaneamente à violência. E é fundamental analisar tais questões para termos um "quadro" mais completo, com a convicção de que sua adequada compreensão tem importância tanto acadêmica quanto política. ${ }^{14}$

As ambiguidades e os paradoxos da ditadura brasileira podem ser explicados, em parte ao menos, pelo influxo de elementos da cultura política. A fórmula modernizadora-autoritária; a hesitação entre uma ditadura clássica e o liberalismo autoritário e a tendência a acomodar no "barco" do poder grupos diferentes, com projetos díspares e às vezes contraditórios, são parte da tradição política do país. A conciliação-negociação como estratégia política é recorrente na história do Brasil, e o episódio de 1964, em linhas gerais, se encaixa no modelo. Nesse sentido, a própria modernização conservadora também não é novidade, já que se manifestou em momentos anteriores, sobretudo na ditadura varguista. Assim, a disposição para a montagem de projetos políticos ambíguos, à base da acomodação, está inscrita na cultura do país, tornando-se opção viável por ter gerado sucesso em ocasiões anteriores.

Quem se propõe a desvelar as complexidades da ditadura enfrenta alguns desafios políticos, principalmente o risco de acusação de complacência com a violência do regime, como se os crimes da ditadura pudessem ser perdoados. Não se trata disso. O regime militar já foi derrotado, felizmente, e pesquisá-lo

\footnotetext{
${ }^{14} \mathrm{O}$ foco aqui é o regime militar, mas é interessante considerar que também no Estado Novo ocorreram jogos de acomodação. Um aspecto a ser destacado foi a estratégia do governo Vargas de abarcar tanto intelectuais conservadores como modernistas em seus quadros, o que gerou políticas culturais e educacionais paradoxais. José Antonio Giusti Tavares (A estrutura do autoritarismo brasileiro. Porto Alegre: Mercado Aberto, 1982) e Kenneth Serbin (Diálogos na sombra: bispos e militares, tortura e justiça social na ditadura. São Paulo: Companhia das Letras, 2001) utilizaram a categoria cultura política para analisar certos aspectos do regime militar.
} 
para além de sua violência repressiva não vai fortalecer o projeto autoritário, ao contrário. Serão mais elevados os custos políticos se evitarmos aprofundar as pesquisas e envolvermos o tema em redoma protetora, contentando-nos em repetir esquemas explicativos consagrados. A verdadeira superação do autoritarismo demanda perceber que o problema não se resumiu a uma casta de malvados que tomaram o poder e impuseram violências à sociedade. O Estado autoritário encontrou o apoio e o beneplácito de muitas pessoas, além de ter contado com a indiferença de outros tantos, este último grupo talvez a maioria. ${ }^{15}$

Assim, é fundamental compreender os mecanismos que explicam o apoio à ditadura, sobretudo as estratégias e as políticas elaboradas pelo Estado para conquistar legitimidade. Esclarecer a complexidade do fenômeno autoritário para, quem sabe, superá-lo demanda revelar a existência de conexões situadas para além do aparelho estatal. É imprescindível perceber que o regime militar, para perdurar, adotou outras armas além da violência. E como durou! A ditadura brasileira foi violenta, como sabemos bem. Entretanto, o Estado autoritário combinou a violência com estratégias de negociação e acomodação, para aplacar as oposições e reduzir a resistência ao seu poder. Nesse sentido, as políticas de modernização objetivavam também a conquista de legitimidade, pois buscavam atrair apoio social e desmobilizar os opositores. Tais estratégias foram particularmente visíveis na relação do Estado com as elites intelectuais, em particular profissionais acadêmicos e produtores culturais.

\section{Jogos de acomodação nas universidades}

As universidades configuram espaço privilegiado para perceber as ambiguidades do regime militar, bem como suas estratégias para aplacar os descontentes e seduzir as elites intelectuais. Observando as políticas estatais para o ensino superior, notamos, em certas circunstâncias, que a repressão foi temperada com estratégias de moderação. Para além da violência política, que

\footnotetext{
${ }^{15}$ Sobre o apoio à ditadura ver AARÃO REIS FILHO, Daniel. Ditadura militar, esquerdas e sociedade. 3 ed. Rio de Janeiro: Zahar, 2005.
} 
não pode ser minimizada, as relações da ditadura com os meios acadêmicos foram permeadas também por jogos de acomodação que transbordam a tipologia binária "resistência x colaboração". As universidades foram um dos alvos principais do projeto modernizador autoritário da ditadura, pelo papel que elas têm na preparação de elites administrativas, de tecnólogos e cientistas, mas também por sua importância política, como formadoras de lideranças intelectuais.

Nessa linha, o novo regime se apropriou do projeto de reforma universitária, uma demanda da esquerda no pré-1964 que defendia, entre outras coisas, a democratização do acesso e da gestão, o fomento à pesquisa e a criação de carreira docente atrativa, sobretudo com o regime de trabalho de dedicação integral. Ensaiada entre 1965 e 1967, a reforma universitária da ditadura foi lançada efetivamente em 1968, impulsionada pela crise estudantil que ela procurava aplacar. A reforma resultou de uma decisão política do comando militar, imposta a uma comunidade acadêmica que, em muitos casos, reagiu com perplexidade. Claro, os traços esquerdistas das demandas reformistas do contexto pré-64 foram desconsiderados, mas alguns pleitos dos acadêmicos foram atendidos. O objetivo era conectar as universidades aos trilhos do projeto desenvolvimentista autoritário, mas a motivação política de desmobilizar o radicalismo estudantil e seduzir os intelectuais foi fundamental.

Modernização conservadora-autoritária é o termo adequado para expressar a reforma universitária da ditadura, processo marcado por paradoxos e impulsionado por forças heterogêneas. Em seu eixo modernizante, a reforma implicou: racionalização de recursos; busca de eficiência; expansão de vagas na graduação; mudanças nos exames vestibulares; aumento da participação da iniciativa privada no ensino superior; reorganização da carreira docente federal, com melhores salários e dedicação exclusiva; criação de departamentos em substituição ao sistema de cátedras; fomento à pesquisa, com aumento nas verbas e financiamentos; criação de cursos de pós-graduação; incremento nas bolsas de estudo para formação de docentes no exterior; e criação de novas universidades federais e estaduais, com um projeto milionário de construção de novos campi.

Para se ter uma ideia dessas mudanças em números, alguns exemplos: em 1964 havia 23 cursos de pós-graduação no Brasil, enquanto em 1974 eles passaram a 400; o número de estudantes universitários subiu de 140 mil, em 1964, para 1 milhão e 300 mil em 1979; as bolsas de pós-graduação financiadas 
pelas agências federais (Capes e CNPq) passaram de aproximadamente mil em 1964 para cerca de 10 mil em 1976.

A infraestrutura universitária e os recursos para pesquisa e pós-graduação aumentaram significativamente no Brasil, mais ainda quando se compara com a situação nas ditaduras vizinhas do Cone Sul, que reduziram verbas para forçar o encolhimento do ensino superior. Entretanto, é preciso destacar que se tratou de crescimento atabalhoado e precário, que entrou em crise com o esgotamento da expansão econômica do regime militar, nos anos 1980.

No eixo conservador das políticas universitárias, a ditadura sofreu o impulso de forças (geralmente de religiosos, intelectuais e de militares conservadores) que não se contentavam tão somente com o expurgo da esquerda revolucionária e da corrupção. Tais grupos tentaram aproveitar o momento para impor a agenda conservadora mais ampla, que contemplasse a luta contra comportamentos morais desviantes, a imposição de censura e a adoção de medidas para fortalecer os valores caros à tradição, sobretudo a pátria e a religião. Por isso, o regime militar combateu e censurou as ideias de esquerda e tudo mais que achasse subversivo - e, naturalmente, os seus defensores; controlou e subjugou o movimento estudantil; criou agências de informação (as Assessorias de Segurança e Informações, ASI) específicas para vigiar a comunidade universitária; censurou a pesquisa, assim como a publicação e circulação de livros; e tentou incutir valores tradicionais por meio de técnicas de propaganda, da criação de disciplinas dedicadas ao ensino de moral e civismo e de iniciativas como o Projeto Rondon.

As universidades eram lugares importantes para a modernização do país, bem como campo de batalha entre os valores conservadores e os ideais de esquerda e de vanguarda; instituições que o regime militar, simultaneamente, procurou modernizar e reprimir, reformar e censurar. Sob o influxo da cultura política brasileira, os governos militares estabeleceram políticas ambíguas, conciliatórias, em que os paradoxos beiram a contradição: demitir professores que depois eram convidados a voltar, para, em seguida, afastá-los novamente; invadir e ocupar universidades que ao mesmo tempo recebiam mais recursos; apreender livros subversivos, mas também permitir que fossem publicados e circulassem. Como explicar o paradoxo de uma ditadura anticomunista que permitiu a contratação de professores marxistas e manteve comunistas em seus cargos públicos, enquanto outros eram barrados e demitidos? Como foi possível, no mesmo contexto, o marxismo ter aumentado sua influência e circulação nas universidades, contra a vontade e os esforços dos órgãos de repressão? 
Outros elementos tradicionais da política brasileira, integrantes da sua cultura, também se fizeram presentes: o Estado autoritário lançou mão de estratégias de cooptação, e vários agentes públicos demonstraram flexibilidade em relação às normas oficiais, com tendência a tangenciar os preceitos legais e confiar mais na autoridade pessoal, nos laços sociais e em arranjos informais. Tais práticas permitiram ao Estado contar com o talento de profissionais provenientes de campo ideológico adversário, mas também propiciaram o amortecimento da repressão, com base na mobilização de fidelidades pessoais e compromissos informais. Em outros termos, certas vezes os atores colocaram no primeiro plano os laços pessoais, deixando para segundo lugar compromissos políticos e afinidades ideológicas.

No caso dos meios acadêmicos, esse aspecto foi mais marcante, pois muitos dos seus membros tinham laços pessoais ou familiares com membros do governo e mesmo das Forças Armadas. Assim, características peculiares da sociedade brasileira, altamente elitizada e com recursos educacionais e culturais concentrados nos estratos superiores, geraram situações em que as lideranças acadêmicas esquerdistas e os líderes do Estado militar pertenciam aos mesmos grupos sociais, o que implicava, muitas vezes, laços de parentesco, amizade ou de convivência escolar anterior.

Isso explica porque, em certas situações, quando as características do regime autorizavam ações repressivas firmes, certos agentes estatais optaram por moderação, tolerância e/ou negociação. Gestões de natureza pessoal permitiram que vetos políticos à contratação de alguns professores fossem contornados; sugestões para aposentadoria compulsória fossem engavetadas; passaportes bloqueados fossem liberados; bolsas de pesquisa retidas fossem autorizadas; condenações judiciais se tornassem mais leves; e, também, alguns presos fossem libertados, e certas prisões, evitadas.

Claro, nem todos os servidores do regime estavam predispostos à moderação, e nem sempre ela funcionou bem, pois centenas de professores e intelectuais perderam cargos ou tiveram sua contratação barrada. ${ }^{16}$ Além disso, é importante lembrar que muita violência ocorreu nos campi

\footnotetext{
${ }^{16}$ Considerando os dois grandes expurgos, em 1964 e 1969, entre aposentadorias e exonerações, pode-se estimar que de 250 a 300 docentes foram afastados das universidades. O número dos que tiveram sua contratação bloqueada por razões ideológicas é mais difícil de precisar, pela escassez de evidências.
} 
universitários, sobretudo nos momentos das invasões policiais, que tiveram lugar em 1968 e, com menor intensidade, em 1977, para não falar dos membros da comunidade universitária presos, torturados e mortos. Por outro lado, a disposição das autoridades para agir com moderação era tanto maior quanto menor o impacto público das atividades promovidas no espaço universitário. Em outras palavras, se o radicalismo acadêmico não transpusesse os muros das faculdades, maiores as chances de ser tolerado e de não atrair medidas repressivas.

No entanto, apesar dessas ressalvas, nas universidades com frequência as vozes moderadas prevaleceram, e a repressão foi temperada com negociação e tentativas de acomodação, em certos casos com a anuência dos órgãos de repressão. Importa ressaltar que esses jogos de acomodação, que se situavam em espaço intermediário entre as opções de resistir ou aderir ao regime militar, implicavam compromissos de mão dupla. Os intelectuais visados pelas agências de repressão que conseguiam escapar de perseguições deveriam comportar-se com discrição, evitando ataques públicos contra a ditadura.

É fundamental levar em conta a existência de tais espaços de acomodação e negociação, tanto para entender a natureza do regime militar quanto porque eles tiveram impacto no processo de superação do autoritarismo. Os expurgos nas universidades teriam sido maiores não fosse a influência moderada em alguns círculos do poder, e graças às estratégias de acomodação que adotaram em certas circunstâncias. Tanto membros do governo quanto dirigentes universitários trabalharam para evitar demissões e liberar contratações, contrariando a indicação de órgãos repressivos. Fizeram-no pelo interesse de contar com o talento de certos profissionais acadêmicos, o que a seus olhos justificava a tolerância política, ou para evitar perda de prestígio junto à comunidade universitária e à opinião pública. Daí ser comum encontrar reitores que tomavam medidas repressivas com uma mão e com a outra protegiam pessoas visadas.

Com isso, evitou-se o expurgo completo da esquerda acadêmica, e, apesar dos esforços da direita militante, que teve força para bloquear muitas contratações de "suspeitos", alguns professores com perfil esquerdista foram admitidos. Essas situações foram mais frequentes antes do AI-5 (entre 1965 e 1968) e depois da distensão (de 1974 em diante), porém ocorreram também durante os anos de repressão mais intensa. Tal não se deu apenas nas universidades, mas também em outros órgãos públicos, da administração direta e indireta, em que algumas pessoas visadas pela repressão foram protegidas por sua competência presumida ou por laços pessoais. Essas 
situações provocaram a ira da direita radical, principalmente de grupos encastelados no aparato de repressão, que, a partir de meados dos anos 1970, passaram a acusar a "infiltração comunista" no governo, elemento que se tornou um dos ingredientes na disputa pelo poder na sucessão do general Geisel.

Os jogos de acomodação analisados sumariamente aqui têm uma peculiaridade que cabe ressaltar: como em todo jogo, as coisas não funcionam se houver apenas um contendor. Explicitando a metáfora, as negociações visando a moderar a repressão sobre as elites intelectuais implicavam concessões mútuas, envolvendo os dois lados. Por isso, não deve causar estranheza que práticas semelhantes tenham marcado também a saída da ditadura, estimulando o pacto e o arranjo entre os círculos no poder e as forças de oposição. Creio residir aí uma explicação para o caráter relativamente indolor (para os próceres do regime militar) da transição pósautoritária no Brasil, marcada pela ausência de punições contra os agentes da violência estatal e pela acomodação das antigas elites políticas no novo quadro "democrático".

O processo de saída do regime militar e de construção da democracia foi marcado por acomodações e conciliações que permitiram reduzir os custos para os agentes da ditadura. Porém, vale a pena insistir, esse caminho foi possível porque mesmo nos momentos intensos da repressão o Estado autoritário mostrou-se transigente em certas situações. A acomodação beneficiou membros das elites sociais, que, embora avessos aos valores oficiais, foram poupados da repressão por considerações pragmáticas ou pela mobilização de laços sociais.

O modo ambíguo e conciliatório como se processou a transição implicou outro preço a pagar do lado dos opositores, para além da aceitação da ausência de punições para os apoiadores da ditadura. Refiro-me ao caráter descontínuo do desmonte das estruturas repressivas, pois, ao passo que a repressão política diminuiu, alguns de seus instrumentos demoraram a ser desmontados, como o SNI e outras agências do gênero, que permaneceram ativas até 1990.

Assim, a influência de traços marcantes da cultura política do país se fez presente também no regime militar, sobretudo a tendência à acomodação interelites. Tendo adotado políticas voltadas simultaneamente para a conservação e a modernização, e mostrado, em certos contextos, indecisão entre erradicar os inimigos ou acomodar-se com parte deles, e oscilado entre a ditadura e as instituições liberais, o Estado autoritário acabou por negociar 
sua saída do poder de maneira igualmente ambígua. Embora com protestos de parcela minoritária da oposição, o arranjo se fez tendo como corolário o esquecimento de todos os crimes cometidos e a incorporação de antigos apoiadores do regime ao novo quadro político.

Considerando os países do cone sul, o Brasil é o único em que os agentes repressivos da Ditadura continuam impunes, apesar das pressões em contrário. Tradicionalmente receptiva a acordos e acomodações, mais uma vez, a força da cultura política se faz valer. E as ações de alguns integrantes do regime militar que aceitaram arranjos para diminuir o impacto da repressão contribuíram para esse quadro, pois, ao reduzir a escala dos atingidos, eles aumentaram, no campo das antigas oposições, o número de lideranças dispostas a negociar e a se acomodar com seus antigos inimigos.

\section{Referências}

AARÃO REIS Filho, Daniel. (2005). Ditadura militar, esquerdas e sociedade. 3. ed. Rio de Janeiro: Zahar.

ALMOND, Gabriel e VERBA, Sidney. (1965). The civic culture: political attitude and democracy in five nations. Boston: LittleBrown.

ANSART, Pierre.

(1978). Ideologias, conflitos e poder. Rio de Janeiro: Zahar.

BACZKO, Bronislaw.

(1985). A imaginação social In: Leach, Edmund et Alii. Anthropos-Homem. Lisboa, Imprensa Nacional/Casa da Moeda.

BARBOZA FILH0, Rubem.

(2000). Tradição e artifício. Iberismo e barroco na formação americana. Belo Horizonte: UFMG.

BERSTEIN, Serge.

(1988). A cultura política. In RIOUX \& SIRINELLI (org.). Para uma história cultural. Lisboa: Estampa.

BERSTEIN, Serge (org.). (1999). Les cultures politiques en France. Paris: Éditions du Seuil.
(2009). "Culturas políticas e historiografia". In Cecília Azevedo; Denise Rollemberg; Paulo Knauss; Maria Fernanda Baptista Bicalho; e Samantha Viz Quadrat. Cultura Política, Memória e Historiografia. Rio de Janeiro: FGV.

CARVALH0, José Murilo de. ]

(1987). Os bestializados. O Rio de Janeiro e a República que não foi. São Paulo: Companhia das Letras.

(1990). A Formação das Almas. O imaginário da República no Brasil. São Paulo: Companhia das Letras.

FA0RO, Raymundo.

(1975). Os donos do poder: a formação do patronato político brasileiro. 2 ed. Porto Alegre: Globo.

GIRARDET, Raoul.

(1987). Mitos e mitologias políticas. São Paulo: Companhia das Letras.

MOISÉS, José Álvaro.

(2008). Cultura política, instituições e democracia. Lições da experiência brasileira. Revista Brasileira de Ciências Sociais. São Paulo, vol.23, no66, pp.11-43. 
M0TTA, Rodrigo Patto Sá.

(2009). Desafios e possibilidades na apropriação de cultura política pela historiografia In: Culturas Políticas na História: Novos Estudos. Belo Horizonte: Argvmentvm, p. 13-37.

(2014). As universidades e o regime militar. Cultura política brasileira e modernização autoritária. Rio de Janeiro: Jorge Zahar.

NAPOLITANO, Marcos.

(2010). “Vencer Satã só com orações”: políticas culturais e cultura de oposição no Brasil dos anos 1970 In Denise Rollemberg; e Samantha Quadrat (Orgs.); A construção social dos regimes autoritários Legitimidade, consenso e consentimento no século XX. Brasil e América Latina. Rio de Janeiro: Civilização Brasileira, pp.145-174.

PEREIRA, Anthony. Political (in) justice. Authoritarianism and the rule of law in Brazil, Chile and Argentina. Pittsburgh: University of Pittsburgh Press, 2005.

RIDENTI, Marcelo.

(2010). Brasilidade revolucionária: um século de cultura e política. São Paulo: UNESP.
RODRIGUES, José Honório.

(1965). Conciliação e reforma no Brasil: um desafio histórico-cultural. Rio de Janeiro: Nova Fronteira.

SCHMITTER, Philippe C.

(1971). Interest conflict and political change in Brazil. Stanford: Stanford University Press.

SERBIN, Kenneth.

(2001). Diálogos na sombra: bispos e militares, tortura ejustiça social na ditadura. São Paulo: Companhia das Letras.

TAVARES, José Antonio Giusti.

1982. A estrutura do autoritarismo brasileiro. Porto Alegre: Mercado Aberto.

VIANNA, Francisco José de Oliveira.

(1949). Instituições políticas brasileiras. São Paulo: José Olympio.

\section{Recebido em}

abril de 2014

Aprovado em

julho de 2014 